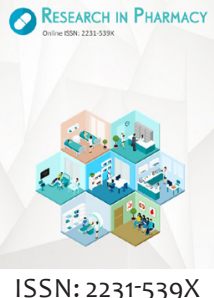

ISSN: 2231-539X
Received: April 17, 2018 Accepted: May 20, 2018 Published: May 28, 2018

*Corresponding Author: Anita Pandey Email: anita@gbpihed.nic.in; anitapandey333@gmail.com

\section{Selection of solvent and extraction method for determination of antimicrobial potential of Taxus wallichiana Zucc.}

\author{
Priyanka Adhikari', Anita Pandey ${ }^{1 *}$, Vasudha Agnihotri², Veena Pande \\ ${ }^{1}$ Centre for Environmental Assessment and Climate Change, G.B. Pant National Institute of Himalayan Environment \\ and Sustainable Development, Kosi-Katarmal, Almora, Uttarakhand 263643 , India, ${ }^{2}$ Centre for Land and Water \\ Resource Management, G.B. Pant National Institute of Himalayan Environment and Sustainable Development, \\ Kosi-Katarmal, Almora, Uttarakhand 263 643, India, ${ }^{3}$ Department of Biotechnology, Kumaun University, Bhimtal \\ Campus, Bhimtal, Uttarakhand 263 136, India
}

\begin{abstract}
Antimicrobial potential of different plant parts (needle, stem and bark) of Himalayan yew (Taxus wallichiana Zucc.) has been investigated with particular reference to selection of solvents and extraction methods. Two extraction methods (maceration and soxhlet), seven solvents (methanol, ethanol, acetone, chloroform, ethyl acetate, di chloro methane and petroleum ether), and 3 groups of microorganisms (bacteria, actinobacteria and fungi) were considered for detection of antimicrobial activity. While qualitative estimations were done using agar well diffusion method, quantitative analysis was based on dilution method. All the plant part showed significant activity against all 3 groups of microorganisms in qualitative bioassays; maximum being in case of needles. Among solvents, ethanolic extract of needles (maceration) showed highest antibacterial activity $(15.33 \pm 0.25 \mathrm{~mm})$. Growth of actinobacteria was inhibited maximum $(22.0 \pm 0.26 \mathrm{~mm}$ ) by the methanolic extracts of needles (maceration). Ethyl acetate extract of needles (soxhlet) showed higher antifungal activity $(8.67 \pm 0.23 \mathrm{~mm})$. Antibacterial and antifungal activities were higher in maceration and soxhlet methods, respectively. The most affected group among the test microorganisms was bacteria which may be due to their prokaryotic organization. This was also supported by the low minimum inhibitory concentration (MIC) values. Di chloro methane and petroleum ether did not show any antifungal activity. The antimicrobial activity of various plant parts of T. wallichiana varied with respect to the solvent as well as the extraction method. The study will have implications in selection of the use of solvent and the extraction procedure in obtaining the antimicrobial metabolites from various plant parts of T. wallichiana.
\end{abstract}

KEY WORDS: Taxus wallichiana, antimicrobials, minimum inhibitory concentration (MIC), solvent, extraction method

\section{INTRODUCTION}

Antibiotic resistance phenomenon and development of the side effects due to consumption of microbe derived antibiotics suggested the need for alternate sources for combating the infectious diseases. In this perspective, plant based antimicrobials (derived from medicinal plants, in particular) are increasingly receiving attention for harnessing their potential in production of antimicrobial substances, as safer source of antibiotics. The Himalayan mountain ecosystem is well known for harbouring a plethora of medicinal and aromatic plants along with their domestication and cultivation for commercial purposes [1,2]. Plant extracts from a variety of medicinal plants showed potential antioxidant properties $[3,4]$. Now a day's, antimicrobial compounds are being utilized in various areas such as medical, pharmaceutical, textile and dairy industries, in food-based products, cosmetics, personal care products, etc.

Taxus wallichiana Zucc. (English name: Himalayan Yew; Hindi name: Thuner; family: Taxaceae) is well recognized as a medicinally important evergreen tree that grows under temperate locations of Indian Himalaya. In the Indian subcontinent, the species grows in the northern hemisphere with its distribution in the hills of northern Jammu \& Kashmir, Himachal Pradesh, Uttarakhand and the states in northeast namely Meghalaya, Nagaland, Arunachal Pradesh, and Manipur, at an altitude range of 1800-3300 $\mathrm{m}$. The species has received considerable attention on account of its existing exploitation for the extraction of the drug (taxol) from its bark [5-7]. T. wallichiana is also known for its various ethanomedicinal uses [8] such as the leaf paste is used in treatment of asthma and bronchial disorders.

\footnotetext{
Copyright: $\odot 2018$ The authors. This article is open access and licensed under the terms of the Creative Commons Attribution License (http://creativecommons.org/licenses/by/4.0/) which permits unrestricted, use, distribution and reproduction in any medium, or format for any purpose, even commercially provided the work is properly cited. Attribution - You must give appropriate credit, provide a link to the license, and indicate if changes were made.
} 
Tea, made out of the stem bark of Himalayan yew, has been popular in Himalayan tribal communities for curing cold, cough and hypertension. The species is also known as source of antioxidants [4]. However, the plant species still needs to be highlighted for its antimicrobial potential.

Optimization of plant extracts for any activity, such as production of antimicrobials, is primarily important before isolation of antimicrobial compound(s). Several investigators have worked on the selection of suitable solvents for extraction along with the type of extraction method for assessing bioactive compounds including antimicrobials from different medicinal plants/parts [9-12]. Such reports are lacking in case of T. wallichiana, therefore, the focus of the present study is on the selection of solvent and extraction method in view of achieving maximum antimicrobial potential of the plant species. Therefore, the aim of the present study is to investigate the antimicrobial potential of T. wallichiana with respect to three major groups of microorganisms (bacteria, actinobacteria and fungi) considering seven solvents and two extraction methods.

\section{MATERIALS AND METHODS}

\section{Study Site and Sample Collection}

Plant samples were collected from Jageshwar area in District Almora $\left(29^{\circ} 35^{\prime}-29^{\circ} 39^{\prime} \mathrm{N}\right.$ and $79^{\circ} 59^{\prime}-79^{\circ} 53^{\prime} \mathrm{E}$ ) of Uttarakhand, India. Herbarium of plant needle was submitted to herbarium record of G. B. Pant National Institute of Himalayan Environment and Sustainable Development, KosiKatarmal, Almora, Uttrakhand, India (Voucher number: GBPI 5050). The collected plant parts (needle, stem and bark) were washed, air dried and converted into fine powder for further experimental work.

\section{Chemicals and Microorganisms}

\section{Solvents}

Ethanol, methanol, acetone, chloroform, ethyl acetate, di chloro methane (DCM), and petroleum ether (PET) from Merck, India.

\section{Microbiological media}

Tryptone yeast extract agar (TYE agar), Potato dextrose agar (PDA) from Hi-media, Mumbai, India.

\section{Test microorganisms}

Bacteria: 2 Gram +ve= Bacillus subtilis (NRRL B-30408) and B. megaterium (MCC3124); 4 Gram -ve= Pseudomonas chlororaphis (MCC2693), P. palleroniana (MCC2692), Escherichia coli, and Serratia marcescens (MTCC4822).

Actinobacteria: Nocardia tenirefensis (MCC2012), and Streptomyces sp. (MCC2003).
Fungi: Trichoderma viride (ITCC4402), Paecilomyces variotii (ITCC3710), Aspergillus niger (ITCC2546), Fusarium oxysporum (ITCC4219), F. solani (ITCC 5017), Pythium afertile (ITCC4217), Trametes hirsuta (MTCC11397), Phytophthora sp., Alternaria alternata (ITCC807), and Penicillum purpurogenum (ITCC3684).

These test microorganisms were taken from the microbial culture collection, established in the Microbiology Lab of the Institute (GBPNIHESD). Accession numbers shown in the parentheses have been allocated by the National/International depositories: NRRL (Northern Regional Research Laboratory, Agricultural Research Service Patent Culture Collection, United States Department of Agriculture, Illinois; MCC (Microbial Culture Collection, National Centre for Cell Science, Pune, India); MTCC (Microbial Type Culture Collection and Gene Bank, Institute of Microbial Technology, Chandigarh, India); ITCC (Indian Type Culture Collection, Indian Agricultural Research Institute, New Delhi, India).

\section{Extraction}

Needle, bark and stem were extracted through maceration and soxhlet methods, separately, using seven selected solvents (methanol, ethanol, acetone, chloroform, ethyl acetate, PET and DCM).

\section{Maceration}

$2 \mathrm{~g}$ of plant sample (needle, bark, and stem, separately) was mixed in different solvents, separately, in a ratio of 1:5 (dry powder: solvents). The mouth of conical flask was sealed with the para- film. Samples were macerated using rotary shaker (Remi) at $160 \mathrm{rpm}$ for $24 \mathrm{~h}$.

Soxhlet

$2 \mathrm{~g}$ of plant sample was placed in thimble and extracted with selected solvent, separately, in soxhlet extraction unit (MAC). Extraction was repeated until the sample extract became of color less.

\section{Bioassays for Determination of Antimicrobial Potential of T. wallichiana Extracts}

\section{Plate based bioassays}

For qualitative estimation of antimicrobial potential of T. wallichiana extracts, agar plate based bioassays were performed using disc diffusion method. Bacterial and actinobacterial culture suspensions were prepared in TYE agar while fungal culture suspension was prepared in PDA. $100 \mu \mathrm{l}$ of all the test organisms (separately) were spread uniformly on the respective agar surface (TYE agar plates for bacteria and actinobacteria, and PD agar plates for fungus) with the help of a glass spreader. Sterilized $5 \mathrm{~mm}$ filter paper (Whatman No. 1) discs were placed over the agar surface with the help of sterile forceps. $15 \mu$ l of extract was loaded over the agar disc. The plates 
were then incubated at $25^{\circ} \mathrm{C}$. The results were recorded on the basis of zone of inhibition $(\mathrm{mm})$ after $24 \mathrm{~h}$ for bacteria and $120 \mathrm{~h}$ for actinobacteria and fungi. All the experiments were performed in triplicate.

\section{Quantitative Estimation/Minimum Inhibitory Concentration (MIC)}

MIC was determined following Clinical and Laboratory Standard Institute methodology [13]. Bacterial and actinobacterial culture suspensions were prepared in TYE while fungal cultures were prepared in PD broth. For determination of MIC, $1 \mathrm{ml}$ extract was diluted using different concentration ranging from 100 to $1000 \mu \mathrm{g} / \mathrm{ml}, 1 \mathrm{ml}$ test organism and $8 \mathrm{ml}$ broth was taken in sterile test tube, and then incubated at $25^{\circ} \mathrm{C}$ for $24 \mathrm{~h}$ for bacteria and $120 \mathrm{~h}$ for actinobacteria and fungi. Control was prepared in two sets, one containing broth medium and test organism while the other containing broth medium and extract. After $24 \mathrm{~h}$, the MIC values were recorded on the basis of the lowest concentration showing absence of growth in the tubes. The test was further confirmed by plating on TYE agar and PDA medium.

\section{Statistical Analysis}

The data was expressed as the means \pm standard errors (SE) from experiments, performed in triplicate. Statistical significance was determined using student's t-test. A $p$ value $<0.05$ was considered as significant. Homogenizing grouping of all microorganisms was done separately using Duncan test in SPSS version 20.

\section{RESULTS}

\section{Extraction Yield with Reference to Extraction (Soxhlet and Maceration) Methods}

Figure 1 shows the extract yield of different plant parts of T. wallichiana (needle, stem and bark) extracted by different solvents and extraction methods. The extraction yield was recorded highest in stem in soxhlet ethanolic extract, while it was at par in case of acetone and methanol in soxhlet method. The extraction yield in bark was recorded highest in ethanolic extract in soxhlet and lowest in PET extract of maceration method. In needles, the yield was estimated higher in soxhlet methanolic and acetone extracts in comparison to the other extracts and it was recorded lowest in chloroform extract obtained by maceration method. Among all the plant parts of T. wallichiana, including the needle, stem and bark extracts following the maceration and soxhlet methods, the highest extract yield was found in needle extracts obtained by soxhlet method. Higher extract yield with polar solvents indicated towards the presence of more polar molecules in T. wallichiana. Low extract yield in ethyl acetate in comparison to other polar solvent was probably due to the poor dielectric constant. The extract weight of different part of T. wallichiana used were significantly different at $\mathrm{p}<0.029$.

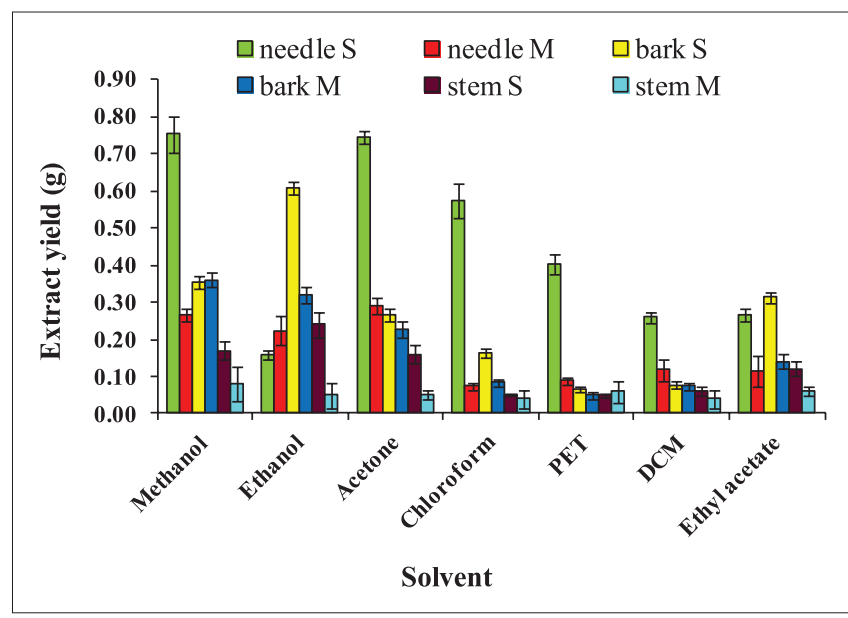

Figure 1: Extract yield of stem, needle and bark of Taxus wallichiana. $\mathrm{S}=$ soxhlet, $\mathrm{M}=$ maceration, $\mathrm{PET}=$ petroleum ether, $\mathrm{DCM}=$ di chloro methane extract

\section{Antimicrobial Activity in Plant (Needle, Stem and Bark) Extracts}

\section{Qualitative plate based bioassays}

Needle, bark and stem extracts of T. wallichiana showed antimicrobial activity against all the three groups of microorganisms viz. bacteria, actinobacteria and fungi. Tables 1-3 and Figure 2 represent the antimicrobial activity of needle, bark and stem extracts, separately, in both the extraction methods. While all the solvents were effective in revealing the antibacterial activity in T. wallichiana extracts, PET and DCM showed selectivity in this aspect. Further, these two solvents (PET and DCM) did not show any activity against actinobacteria and fungi. Amongst bacteria, species of Bacillus were the most affected ones in terms of showing inhibition by T. wallichiana extracts, while E. coli was the least affected. On the basis of Duncan test used for homogeneous grouping of microorganisms separately, out of the two test species of Bacillus, B. subtilis showed higher inhibition in case of ethanolic extract of macerated needles and B. megaterium in case of methanolic extract of macerated needles. The inhibition of E. coli in macerated needle acetone extract, $S$. marcescens in macerated needle and bark methanolic extracts, $P$. chlororaphis in macerated needle and bark ethanolic extracts and $P$. palleroniana in soxhlet needle methanolic extract was at par. The actinobacterial species, N. tenirefensis and Streptomyces sp., were highly inhibited in macerated methanolic needle extract and macerated needle and bark methanolic extracts, respectively.

Among 10 test fungal species, only 5 (A. niger, F. oxysporum, F. solani, P. variotii and T. hirsuta) got affected by the T. wallichaina extracts. Species of Alternaria, Penicillum, Phytophthora, Pythium and Trichoderma were not at all affected by the T. wallichaina extracts. The fungal species namely A. niger, F. oxysporum, and F. solani were inhibited maximally in soxhlet needle ethyl acetate extract. Likewise, P. variotii was maximally affected in macerated needle ethanolic extract and T. hirsuta in bark ethanolic extract. Figures 3-5 present the comparative 
Table 1: Antimicrobial activity of T. wallichiana needle

\begin{tabular}{|c|c|c|c|c|c|c|c|c|c|c|}
\hline \multirow[t]{3}{*}{ Microorganism } & \multicolumn{10}{|c|}{ Zone of inhibition (mm) } \\
\hline & \multicolumn{2}{|c|}{ Methanol } & \multicolumn{2}{|c|}{ Ethanol } & \multicolumn{2}{|c|}{ Acetone } & \multicolumn{2}{|c|}{ Chloroform } & \multicolumn{2}{|c|}{ Ethyl acetate } \\
\hline & Sox & Mac & Sox & Mac & Sox & Mac & Sox & Mac & Sox & Mac \\
\hline \multicolumn{11}{|c|}{ Gram+ve } \\
\hline B. subtilis & $12.00 \pm 0.32$ & $14.7 \pm 0.32$ & $8.80 \pm 0.28$ & $15.33 \pm 0.25$ & $5.00 \pm 0.35$ & $13.33 \pm 0.18$ & $6.00 \pm 0.22$ & $6.0 \pm 0.22$ & $2.46 \pm 0.36$ & - \\
\hline \multicolumn{10}{|c|}{ Gram -ve } & - \\
\hline E. coli & $8.33 \pm 0.20$ & $9.00 \pm 0.34$ & $6.34 \pm 0.44$ & $7.30 \pm 0.38$ & $6.67 \pm 0.28$ & $10.40 \pm 0.43$ & $2.70 \pm 0.20$ & $2.7 \pm 0.20$ & $2.14 \pm 0.15$ & $2.67 \pm 0.37$ \\
\hline P. chlororaphis & $8.95 \pm 0.39$ & $10.32 \pm 0.19$ & $8.00 \pm 0.51$ & $12.40 \pm 0.20$ & $7.00 \pm 0.25$ & $8.56 \pm 0.43$ & $2.70 \pm 0.37$ & $4.7 \pm 0.37$ & $5.00 \pm 0.16$ & $6.32 \pm 0.43$ \\
\hline P. palleroniana & $10.11 \pm 0.26$ & $9.37 \pm 0.26$ & $8.00 \pm 0.57$ & $8.33 \pm 0.39$ & $8.24 \pm 0.47$ & $8.67 \pm 0.31$ & $3.27 \pm 0.24$ & $5.2 \pm 0.24$ & $6.33 \pm 0.51$ & $7.33 \pm 0.33$ \\
\hline S. marcescens & $9.00 \pm 0.29$ & $15.20 \pm 0.56$ & $11.00 \pm 0.23$ & $\begin{array}{r}12.67 \pm 0.44 \\
\text { Acti }\end{array}$ & $\begin{array}{l}10.33 \pm 0.45 \\
\text { inobacteria }\end{array}$ & $13.98 \pm 0.34$ & $7.90 \pm 0.31$ & $2.9 \pm 0.31$ & $4.50 \pm 0.38$ & $5.33 \pm 0.26$ \\
\hline N. tenirefensis & $22.00 \pm 0.26$ & $22.00 \pm 0.26$ & $7.33 \pm 0.25$ & $10.67 \pm 0.31$ & $11.00 \pm 0.45$ & $7.00 \pm 0.21$ & $5.00 \pm 0.30$ & $5.0 \pm 0.20$ & $2.50 \pm 0.58$ & $8.45 \pm 0.33$ \\
\hline \multicolumn{10}{|c|}{ 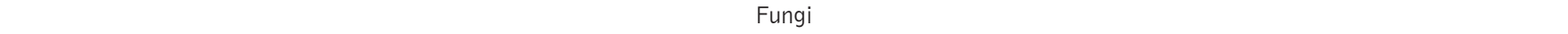 } & $7.00 \pm 0.31$ \\
\hline A. niger & $4.33 \pm 0.39$ & $6.76 \pm 0.31$ & $7.20 \pm 0.43$ & $7.67 \pm 0.43$ & $6.34 \pm 0.56$ & $6.34 \pm 0.34$ & $3.00 \pm 0.44$ & $3.0 \pm 0.37$ & $8.00 \pm 0.33$ & $2.76 \pm 0.09$ \\
\hline F. oxysporum & $2.37 \pm 0.32$ & $3.81 \pm 0.32$ & $2.30 \pm 0.28$ & $5.78 \pm 0.20$ & - & - & - & - & $8.67 \pm 0.23$ & $7.84 \pm 0.21$ \\
\hline F. solani & $4.45 \pm 0.20$ & $2.33 \pm 0.31$ & $3.33 \pm 0.23$ & $5.32 \pm 0.26$ & $3.17 \pm 0.37$ & $5.65 \pm 0.26$ & $4.30 \pm 0.21$ & $4.3 \pm 0.21$ & $6.40 \pm 0.05$ & $2.42 \pm 0.26$ \\
\hline P. variotii & $4.32 \pm 0.45$ & $5.76 \pm 0.42$ & $6.12 \pm 0.07$ & $6.67 \pm 0.35$ & $5.40 \pm 0.35$ & $6.40 \pm 0.26$ & $3.30 \pm 0.26$ & $3.3 \pm 0.26$ & $3.50 \pm 0.06$ & $2.98 \pm 0.37$ \\
\hline T. hirsuta & $4.00 \pm 0.40$ & $4.27 \pm 0.20$ & $3.00 \pm 0.25$ & $3.00 \pm 0.25$ & - & - & - & - & - & - \\
\hline
\end{tabular}

(Sox $=$ soxhlet, $\mathrm{Mac}=$ maceration)

Table 2: Antimicrobial activity of T. wallichiana bark

\begin{tabular}{|c|c|c|c|c|c|c|c|c|c|c|}
\hline \multicolumn{11}{|c|}{ Zone of inhibition (mm) } \\
\hline \multirow[t]{2}{*}{ Microorganism } & \multicolumn{2}{|c|}{ Methanol } & \multicolumn{2}{|c|}{ Ethanol } & \multicolumn{2}{|c|}{ Acetone } & \multicolumn{2}{|c|}{ Chloroform } & \multicolumn{2}{|c|}{ Ethyl acetate } \\
\hline & Sox & Mac & Sox & Mac & Sox & Mac & Sox & Mac & Sox & Mac \\
\hline \multicolumn{11}{|c|}{ Gram+ve } \\
\hline B. subtilis & $7.00 \pm 0.24$ & $14.32 \pm 0.32$ & $8.00 \pm 024$ & $15.33 \pm 0.36$ & $5.00 \pm 0.15$ & $13.49 \pm 0.18$ & $6.00 \pm 0.22$ & $6.0 \pm 0.22$ & $4.46 \pm 0.36$ & $4.76 \pm 0.33$ \\
\hline B. megaterium & $10.33 \pm 0.32$ & $13.74 \pm 0.16$ & $9.33 \pm 0.28$ & $13.97 \pm 0.25$ & $\begin{array}{l}5.67 \pm 0.17 \\
\text { aram -ve }\end{array}$ & $13.33 \pm 0.43$ & $5.40 \pm 0.32$ & $5.4 \pm 0.32$ & $4.34 \pm 0.34$ & $5.46 \pm 0.36$ \\
\hline E. coli & $6.00 \pm 0.24$ & $9.30 \pm 0.34$ & $5.00 \pm 0.42$ & $7.00 \pm 0.38$ & $5.67 \pm 0.23$ & $10.00 \pm 0.13$ & $2.70 \pm 0.20$ & $2.7 \pm 0.20$ & $2.14 \pm 0.32$ & $2.67 \pm 0.38$ \\
\hline P. chlororaphis & $8.67 \pm 0.34$ & $10.32 \pm 0.29$ & $6.00 \pm 0.28$ & $12.00 \pm 0.20$ & $6.00 \pm 0.35$ & $8.00 \pm 0.43$ & $4.70 \pm 0.37$ & $4.7 \pm 0.37$ & $5.00 \pm 0.16$ & $6.32 \pm 0.41$ \\
\hline P. palleroniana & $7.57 \pm 0.32$ & $9.60 \pm 0.24$ & $8.00 \pm 0.37$ & $7.33 \pm 0.39$ & $8.67 \pm 0.27$ & $8.32 \pm 0.31$ & $5.27 \pm 0.24$ & $5.2 \pm 0.24$ & $6.33 \pm 0.35$ & $7.33 \pm 0.35$ \\
\hline \multicolumn{11}{|c|}{ Actinobacteria } \\
\hline N. tenirefensis & $18.70 \pm 0.36$ & $20.00 \pm 0.27$ & $7.43 \pm 0.35$ & $10.67 \pm 0.31$ & $10.00 \pm 0.45$ & $7.00 \pm 0.28$ & $5.00 \pm 0.30$ & $5.0 \pm 0.33$ & $3.50 \pm 0.58$ & $8.45 \pm 0.28$ \\
\hline Streptomyces sp. & $11.00 \pm 0.43$ & $16.00 \pm 0.31$ & $9.52 \pm 0.39$ & $11.33 \pm 0.27$ & $\begin{array}{l}7.67 \pm 0.34 \\
\text { Fungi }\end{array}$ & $7.27 \pm 0.37$ & $11.00 \pm 0.37$ & $11.00 \pm 0.27$ & $6.50 \pm 0.47$ & $7.00 \pm 0.21$ \\
\hline A. niger & $4.23 \pm 0.33$ & $6.76 \pm 0.33$ & $7.00 \pm 0.28$ & $7.43 \pm 0.29$ & $6.56 \pm 0.56$ & $6.0 \pm 0.24$ & $3.00 \pm 0.14$ & $3.0 \pm 0.37$ & $6.13 \pm 0.33$ & $1.76 \pm 0.26$ \\
\hline F. oxysporum & $2.97 \pm 0.34$ & $3.21 \pm 0.34$ & $2.67 \pm 0.38$ & $4.00 \pm 0.22$ & $3.54 \pm 0.24$ & $3.87 \pm 0.24$ & $2.67 \pm 0.24$ & $2.23 \pm 0.24$ & $7.84 \pm 0.21$ & $6.67 \pm 0.25$ \\
\hline F. solani & $4.45 \pm 0.25$ & $2.33 \pm 0.24$ & $4.73 \pm 0.34$ & $5.32 \pm 0.24$ & $3.67 \pm 0.37$ & $5.65 \pm 0.26$ & $4.30 \pm 0.31$ & $4.3 \pm 0.21$ & $6.00 \pm 0.05$ & $2.32 \pm 0.36$ \\
\hline P. variotii & $3.97 \pm 0.41$ & $5.76 \pm 0.43$ & $6.00 \pm 0.27$ & $6.57 \pm 0.32$ & $5.33 \pm 0.35$ & $6.00 \pm 0.26$ & $3.30 \pm 0.26$ & $3.3 \pm 0.26$ & $3.00 \pm 0.06$ & $1.98 \pm 0.31$ \\
\hline T. hirsuta & $4.20 \pm 0.42$ & $3.67 \pm 0.24$ & $4.10 \pm 0.25$ & $5.08 \pm 0.24$ & - & - & - & - & - & - \\
\hline
\end{tabular}

(Sox=soxhlet, Mac $=$ maceration)

assessment of all the plant part extracts in different solvents and extraction methods in terms of their inhibitory effect on 3 groups of microorganisms viz. bacteria, actinobacteria and fungi. In general, T. wallichiana extracts, made in DCM and PET, showed very low antibacterial activity and no antifungal activity. T. wallichiana extracts in macerated ethanolic, methanolic and acetone showed good antibacterial and antiactinobacterial activity, soxhlet ethyl acetate, methanolic and ethanolic extract showed good antifungal activity, indicated by the formation of zone of inhibition. Ethyl acetate extract showed good inhibition activity againt species of Fusarium (F. oxysporum and F. solani). Furthermore, the aqueous T. wallichiana extracts did not show any antimicrobial activity.

Overall, both the extraction methods (soxhlet and maceration) were effective in revealing the antimicrobial activity. However, if compared on the basis of the groups of the microorganisms, maceration extracts were better in terms of exhibiting inhibition of bacteria and actinobacteria, while soxhlet was better in case of the species of fungi. Among the solvents, macerated ethanolic needle extract showed highest antibacterial activity (15.33 \pm $0.25 \mathrm{~mm}$ ), macerated methanolic needle extract showed highest actinobacterial $(22.0 \pm 0.26 \mathrm{~mm})$, and soxhlet ethyl acetate needle extract was best in exhibiting high antifungal activity $(8.67 \pm 0.23 \mathrm{~mm})$.

\section{Quantitative estimation}

The MIC was performed using five solvents i.e. chloroform, ethyl acetate, acetone, ethanol and methanol, out of which the acetone, ethanol and methanol extracts showed good results against all the group of test microorganisms. The 
Table 3: Antimicrobial activity of T. wallichiana stem

\begin{tabular}{|c|c|c|c|c|c|c|c|c|c|c|}
\hline \multicolumn{11}{|c|}{ Zone of inhibition (mm) } \\
\hline \multirow[t]{2}{*}{ Microorganism } & \multicolumn{2}{|c|}{ Methanol } & \multicolumn{2}{|c|}{ Ethanol } & \multicolumn{2}{|c|}{ Acetone } & \multicolumn{2}{|c|}{ Chloroform } & \multicolumn{2}{|c|}{ Ethyl acetate } \\
\hline & Sox & Mac & Sox & Mac & Sox & Mac & Sox & Mac & Sox & Mac \\
\hline \multicolumn{11}{|c|}{ Gram+ve } \\
\hline B. subtilis & $6.33 \pm 0.25$ & $7.30 \pm 0.25$ & $8.33 \pm 0.27$ & $7.00 \pm 0.37$ & $6.67 \pm 0.26$ & $7.34 \pm 0.39$ & $4.62 \pm 0.44$ & $5.32 \pm 0.37$ & - & - \\
\hline \multicolumn{11}{|c|}{ Gram -ve } \\
\hline E. coli & $8.00 \pm 0.39$ & $8.70 \pm 0.44$ & $8.33 \pm 0.28$ & $8.67 \pm 0.43$ & $8.67 \pm 0.25$ & $9.30 \pm 0.22$ & $7.02 \pm 0.39$ & $9.00 \pm 0.20$ & $6.87 \pm 0.24$ & $7.00 \pm 0.35$ \\
\hline P. chlororaphis & $7.67 \pm 0.22$ & $8.00 \pm 0.28$ & $6.40 \pm 0.34$ & $6.33 \pm 0.51$ & $5.26 \pm 0.25$ & $5.30 \pm 0.28$ & $4.96 \pm 0.27$ & $5.30 \pm 0.23$ & $4.71 \pm 0.18$ & $4.00 \pm 0.20$ \\
\hline P. palleroniana & $7.00 \pm 0.24$ & $7.70 \pm 0.42$ & $8.50 \pm 0.26$ & $8.77 \pm 0.57$ & $5.37 \pm 0.21$ & $6.04 \pm 0.22$ & $6.08 \pm 0.46$ & $6.70 \pm 0.26$ & $4.97 \pm 0.39$ & $4.67 \pm 0.51$ \\
\hline \multicolumn{11}{|c|}{ Actinobacteria } \\
\hline N. tenirefensis & $9.33 \pm 0.36$ & $10.00 \pm 0.25$ & $8.52 \pm 0.26$ & $8.00 \pm 0.20$ & $5.09 \pm 0.26$ & $5.00 \pm 0.26$ & $2.56 \pm 0.23$ & $2.72 \pm 0.13$ & $2.31 \pm 0.36$ & $2.67 \pm 0.16$ \\
\hline Streptomyces sp. & $9.00 \pm 0.34$ & $9.71 \pm 0.38$ & $8.91 \pm 0.31$ & $8.37 \pm 0.39$ & $\begin{array}{l}7.33 \pm 0.38 \\
\text { Fungi }\end{array}$ & $8.00 \pm 0.45$ & $2.85 \pm 0.21$ & $3.00 \pm 0.26$ & $2.14 \pm 0.29$ & $3.00 \pm 0.48$ \\
\hline A. niger & $3.00 \pm 0.39$ & $4.30 \pm 0.25$ & $3.30 \pm 0.34$ & $4.43 \pm 0.23$ & - & $2.30 \pm 0.36$ & - & - & - & - \\
\hline F. oxysporum & - & - & - & - & - & - & - & - & - & - \\
\hline F. solani & $2.47 \pm 0.20$ & $1.70 \pm 0.25$ & $2.03 \pm 0.27$ & $3.00 \pm 0.33$ & - & - & - & - & - & - \\
\hline P. variotii & $2.67 \pm 0.45$ & $3.30 \pm 0.28$ & $4.70 \pm 0.29$ & $3.67 \pm 0.26$ & - & $2.00 \pm 0.36$ & - & - & - & - \\
\hline T. hirsuta & - & - & - & - & - & - & - & - & - & - \\
\hline
\end{tabular}

(Sox $=$ Soxhlet, Mac= maceration)
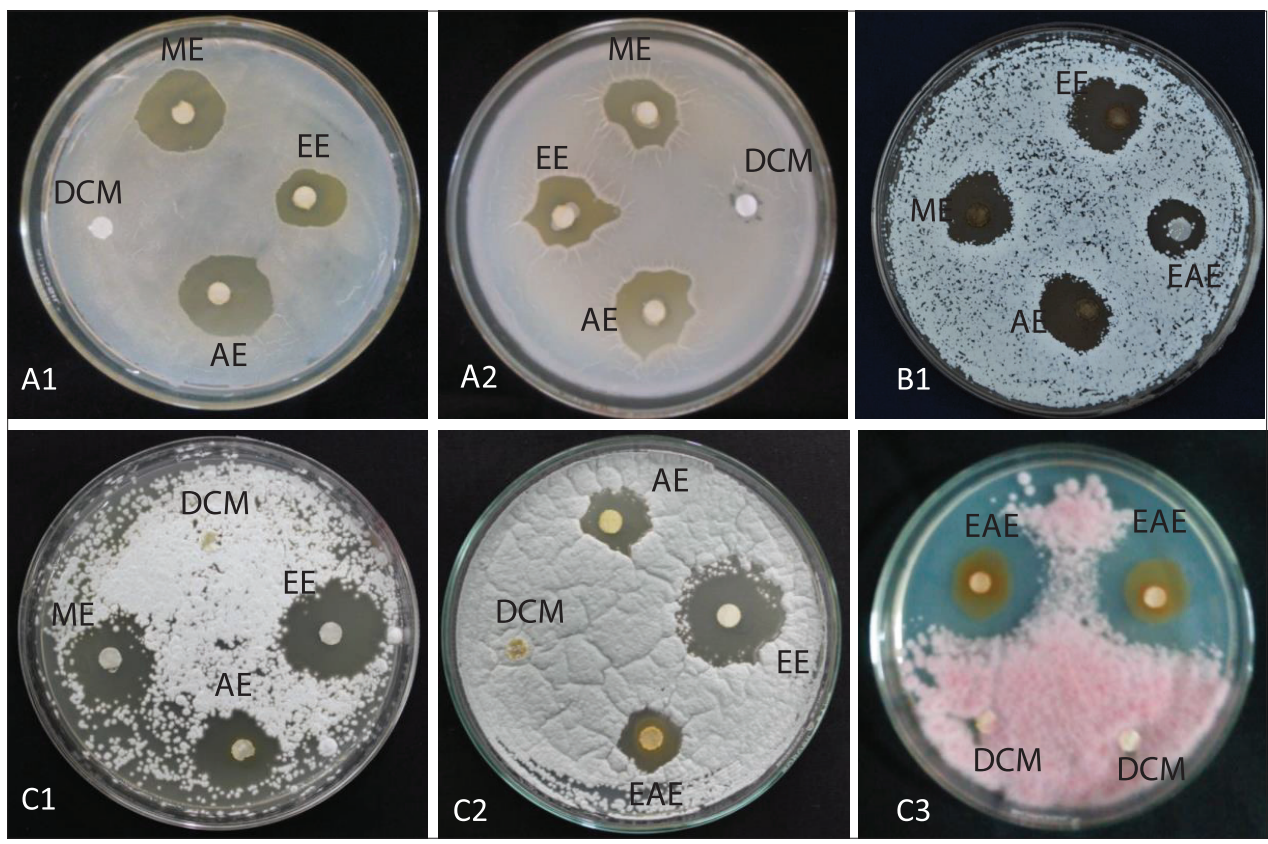

Figure 2: Antimicrobial activity of $T$. wallichiana: (A) Antibacterial activity, (B) Antiactinobacterial activity, and (C) Antifungal activity. DCM=di chloro methane extract, $\mathrm{ME}=$ methanolic extract, $\mathrm{EE}=$ =thanolic extract, $\mathrm{AE}=$ acetone extract, $\mathrm{EAE}=$ ethyl acetate extract

most affected group among the three was bacteria, which is probably due to their prokaryotic organization. This was also supported by the low MIC values. Different microorganisms showed variable response towards these different extracts. The results of MIC of the needle, stem and bark extracts are presented in Tables 4-6.

\section{DISCUSSION}

In the present investigation, extracts of various parts of T. wallichiana have been evaluated for determination of their antimicrobial activity against three major groups of microorganisms bacteria (Gram -ve and Gram +ve), actinobacteria and fungi. The selection of seven different solvents used in this study was based on their polarity and dielectric constant which, starting from the lower dielectric constant values, can be arranged as follows: di chloro methane $(1.3)<$ petroleum ether $(4.3)<$ chloroform $(4.3)<$ ethyl acetate $(6)<$ acetone $(20.7)<$ ethanol $(24.6)<$ methanol (32.7). As depicted in results, extraction yield with polar solvents was higher in comparison to non-polar solvents. These variations may be due to the difference in their polarity as well as dielectric constant, which play vital role in the solubility of phytochemical compounds in respective 
Table 4: Minimum inhibitory concentration (MIC) of T. wallichiana needle extracts

\begin{tabular}{|c|c|c|c|c|c|c|c|c|c|c|}
\hline \multicolumn{11}{|c|}{$\operatorname{MIC}(\mu \mathrm{g} / \mathrm{ml})$} \\
\hline \multirow[t]{2}{*}{ Microorganism } & \multicolumn{2}{|c|}{ Methanol } & \multicolumn{2}{|c|}{ Ethanol } & \multicolumn{2}{|c|}{ Acetone } & \multicolumn{2}{|c|}{ Chloroform } & \multicolumn{2}{|c|}{ Ethyl acetate } \\
\hline & Sox & Mac & Sox & Mac & Sox & Mac & Sox & Mac & Sox & Mac \\
\hline \multicolumn{11}{|c|}{ Gram+ve } \\
\hline B. subtilis & 400 & 150 & 400 & 300 & 400 & 150 & 600 & 550 & 900 & - \\
\hline B. megaterium & 300 & 200 & 300 & 200 & 400 & 200 & 400 & 350 & 900 & - \\
\hline \multicolumn{11}{|c|}{ Gram -ve } \\
\hline E. coli & 400 & 400 & 600 & 600 & 400 & 300 & 800 & 800 & 900 & 850 \\
\hline P. chlororaphis & 400 & 400 & 400 & 300 & 500 & 650 & 200 & 500 & 700 & 700 \\
\hline P. palleroniana & 300 & 600 & 400 & 400 & 300 & 650 & 600 & 300 & 800 & 600 \\
\hline S. marcescens & 300 & 200 & 300 & 300 & 600 & 200 & 750 & 600 & 700 & 800 \\
\hline \multicolumn{11}{|c|}{ Actinobacteria } \\
\hline N. tenirefensis & 100 & 200 & 400 & 300 & 200 & 600 & 700 & 600 & 900 & 300 \\
\hline Streptomyces sp. & 200 & 200 & 500 & 350 & 400 & 600 & 500 & 350 & 700 & 600 \\
\hline \multicolumn{11}{|c|}{ Fungi } \\
\hline A. niger & 700 & 600 & 700 & 800 & 700 & 600 & 500 & 800 & 900 & 900 \\
\hline F. oxysporum & 700 & 600 & 800 & 300 & - & - & 700 & - & 700 & 600 \\
\hline F. solani & 800 & 800 & 900 & 500 & 500 & 500 & 500 & 700 & 700 & 800 \\
\hline P. variotii & 800 & 700 & 500 & 500 & 500 & 600 & 700 & 700 & 800 & 850 \\
\hline T. hirsuta & 700 & 450 & 900 & 800 & - & & - & & - & - \\
\hline
\end{tabular}

(Sox=soxhlet, Mac = maceration)

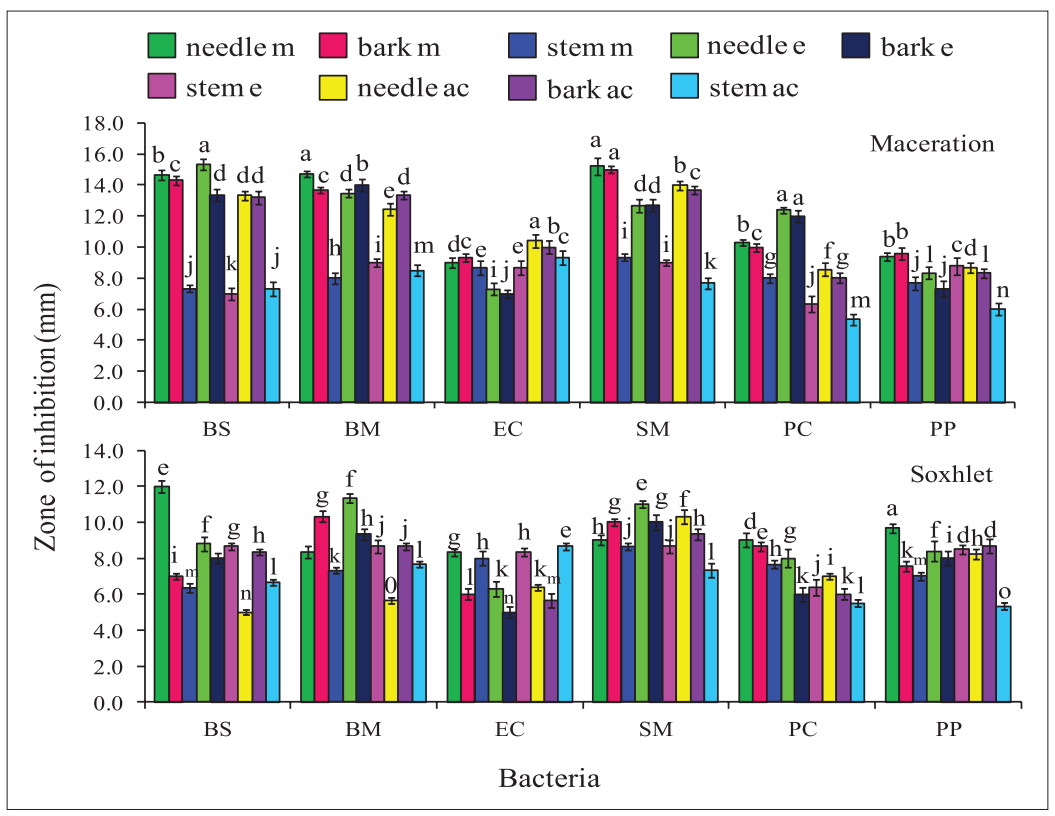

Figure 3: Antibacterial activity of needle, stem and bark of $T$. wallichiana. Methanol $=\mathrm{m}$, ethanol= $\mathrm{e}$, acetone $=\mathrm{ac}, B$. subtilis=BS, $B$. megaterium=BM, E. coli= EC, S. marcescens= SM, P. chlororaphis= PC, P. palleroniana= PP. Homogenize grouping done with respect to antibacterial activity by Duncan test is denoted by the alphabets a-o

solvents. Therefore, this result confirms the effect of solvent system on the extract yield that consequently confirms the richness of this plant species (T. wallichiana) in polar substances $[14,15]$.

The results in the present study coincide with the earlier report of Patel et al. [16] on the antimicrobial activity of T. baccata needles which was demonstrated through the extracts made in different solvents. In the cited study, ethanol extracts of T. baccata showed highest inhibition activity against the selected test bacteria as also in the case of the present study. This preliminary investigation shows that all the polar solvent extracts, such as ethanol, methanol, acetone, ethyl acetate, were active against the tested microorganisms while the non-polar solvent extracts were not effective in inhibiting the microbial growth. These results are also supported by the previous findings of Sati et al. [11] and Nisar et al. [17]. Contrary to these results in various plant species, the extracts of Crossandra infundibuliformis prepared in PET have been reported with higher antifungal activity [18]. An earlier study carried on T. wallichiana needles growing in North-western Frontier Province, Pakistan, reported the absence of antibacterial activity in methanol fractions of the various plant parts [19]. 
Table 5: Minimum inhibitory concentration (MIC) of $T$. wallichiana bark extracts

\begin{tabular}{|c|c|c|c|c|c|c|c|c|c|c|}
\hline \multicolumn{11}{|c|}{$\mathrm{MIC}(\mu \mathrm{g} / \mathrm{ml})$} \\
\hline \multirow[t]{2}{*}{ Microorganism } & \multicolumn{2}{|c|}{ Methanol } & \multicolumn{2}{|c|}{ Ethanol } & \multicolumn{2}{|c|}{ Acetone } & \multicolumn{2}{|c|}{ Chloroform } & \multicolumn{2}{|c|}{ Ethyl acetate } \\
\hline & Sox & $\mathrm{Mac}$ & Sox & $\mathrm{Mac}$ & Sox & $\mathrm{Mac}$ & Sox & $\mathrm{Mac}$ & Sox & Mac \\
\hline \multicolumn{11}{|c|}{ Gram+ve } \\
\hline B. subtilis & 300 & 200 & 500 & 250 & 500 & 700 & 400 & 400 & 400 & 800 \\
\hline B. megaterium & 400 & 300 & 200 & 200 & 500 & 700 & 800 & 500 & 800 & 700 \\
\hline \multicolumn{11}{|c|}{ Gram -ve } \\
\hline E. coli & 500 & 600 & 600 & 600 & 600 & 800 & 800 & 800 & 800 & 400 \\
\hline P. chlororaphis & 400 & 600 & 600 & 400 & 400 & 700 & 700 & 400 & 400 & 650 \\
\hline P. palleroniana & 500 & 500 & 500 & 600 & 600 & 800 & 800 & 400 & 400 & 600 \\
\hline S. marcescens & 300 & 500 & 500 & 300 & 300 & 500 & 500 & 500 & 500 & 750 \\
\hline \multicolumn{11}{|c|}{ Actinobacteria } \\
\hline N. tenirefensis & 400 & 600 & 600 & 300 & 300 & 300 & 300 & 700 & 700 & 700 \\
\hline Streptomyces sp. & 600 & 600 & 600 & 600 & 600 & 400 & 400 & 600 & 600 & 700 \\
\hline \multicolumn{11}{|c|}{ Fungi } \\
\hline A. niger & 900 & 850 & 900 & 700 & 700 & 650 & 700 & 900 & - & - \\
\hline F. oxysporum & - & 700 & & 900 & - & 700 & - & 900 & - & - \\
\hline F. solani & 800 & 900 & 800 & 600 & 900 & 800 & 900 & 950 & 700 & 700 \\
\hline P. variotii & 800 & 700 & 700 & 700 & 800 & 600 & 800 & 950 & - & - \\
\hline T. hirsuta & 900 & 900 & 800 & 900 & - & - & - & - & - & - \\
\hline
\end{tabular}

(Sox=soxhlet, Mac= maceration)

Table 6: Minimum inhibitory concentration (MIC) of T. wallichiana stem extracts

\begin{tabular}{|c|c|c|c|c|c|c|c|c|c|c|}
\hline \multicolumn{11}{|c|}{$\mathrm{MIC}(\mu \mathrm{g} / \mathrm{ml})$} \\
\hline \multirow[t]{2}{*}{ Microorganism } & \multicolumn{2}{|c|}{ Methanol } & \multicolumn{2}{|c|}{ Ethanol } & \multicolumn{2}{|c|}{ Acetone } & \multicolumn{2}{|c|}{ Chloroform } & \multicolumn{2}{|c|}{ Ethyl acetate } \\
\hline & Sox & Mac & Sox & Mac & Sox & Mac & Sox & Mac & Sox & Mac \\
\hline \multicolumn{11}{|c|}{ Gram+ve } \\
\hline B. subtilis & 500 & 600 & 600 & 700 & 700 & 950 & 950 & 700 & - & - \\
\hline B. megaterium & 600 & 600 & 600 & 700 & 700 & 950 & 950 & 700 & - & - \\
\hline \multicolumn{11}{|c|}{ Gram -ve } \\
\hline E. coli & 650 & 600 & 600 & 650 & 650 & 900 & 900 & 800 & 800 & 650 \\
\hline P. chlororaphis & 650 & 650 & 650 & 600 & 600 & 850 & 850 & 850 & 850 & 800 \\
\hline P. palleroniana & 600 & 650 & 650 & 650 & 650 & 800 & 800 & 800 & 800 & 700 \\
\hline S. marcescens & 750 & 600 & 600 & 700 & 700 & 900 & 900 & 900 & 900 & 700 \\
\hline \multicolumn{11}{|c|}{ Actinobacteria } \\
\hline N. tenirefensis & 450 & 300 & 700 & 600 & 600 & 950 & 950 & 800 & 800 & 800 \\
\hline Streptomyces sp. & 450 & 300 & 700 & 600 & 600 & 900 & 900 & 850 & 850 & 800 \\
\hline \multicolumn{11}{|c|}{ Fungi } \\
\hline A. niger & 850 & 800 & 800 & 800 & - & 700 & - & - & - & - \\
\hline F. oxysporum & - & - & - & - & - & - & - & - & - & - \\
\hline F. solani & 900 & 900 & 800 & 800 & - & 700 & - & - & - & - \\
\hline P. variotii & 950 & 750 & 850 & 850 & - & 800 & - & - & - & - \\
\hline T. hirsuta & - & - & - & - & - & - & - & - & - & - \\
\hline
\end{tabular}

(Sox $=$ soxhlet, Mac= maceration)

Demonstration of the antibacterial activity in the methanolic extracts of all the plant parts (needles, stem and bark) of T. wallichiana belonging to Indian Himalayan region, in the present study, appears to be an indicative of the influence of different climatic conditions.

Among the two extraction methods used, the soxhlet method resulted in higher yield in comparison to the maceration method. Interestingly, the antimicrobial activity was recorded higher in macerated extracts. This could be attributed to the higher solubility of extractable bioactive components such as phenols, flavanols, tannin and flavonoids, having antimicrobial potential. These results were also supported by the earlier findings of Felhi et al. [15,20]. The cited reports have shown that extraction in different solvents influence the extraction yield of total phenol content along with the antioxidants and antimicrobial activity. The variation in the extraction yield could also be due to the difference in polarity of the solvents used which plays a key role in increasing the solubility of phytochemical compounds [21,22].

Significant variation in MIC recorded in all the extracts demonstrated towards the variable contribution of the method of extraction and selection of solvent as well as the type of test microorganisms used. Also, variation in MIC of different plant extracts may arise from variation in their chemical constituents and their volatiles indicating the presence of one or more chemical moieties in the crude extract contributing towards the antimicrobial activity. This is proven by the varying results showing highest antifungal 
activity in needle ethyl acetate extract (soxhlet), and highest antibacterial activity in leaf ethanolic extract (maceration). Ethyl acetate soxhlet needle extracts are likely to contain

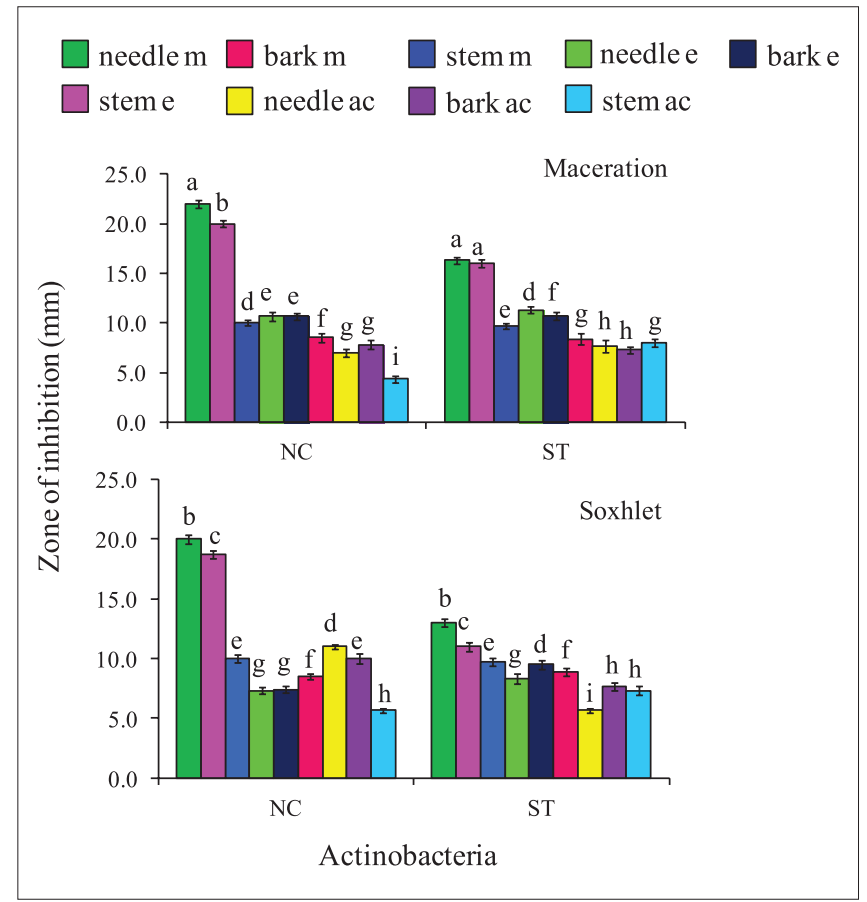

Figure 4: Antiactinobacterial activity of needle, stem and bark of $T$. wallichiana. Methanol $=\mathrm{m}$, ethanol $=\mathrm{e}$, acetone $=\mathrm{ac}, \mathrm{N}$. tenirefensis= NC, Streptomyces sp.= ST. Homogenize grouping done with respect to antiactinobacterial activity by Duncan test is denoted by the alphabets a-i the compounds with the capability to target eukaryotic cells, while ethanolic macerated needle extract composition is suitable to target prokaryotic cells which needs to be further explored $[23,24]$.

On the basis of the results obtained, it is concluded that among the various plant parts, needles of T. wallichiana possess relatively higher antimicrobial activity. As needle is renewable part of the plant, its utilization for harnessing the antimicrobial potential is recommended. For further isolation of the antibacterial and antifungal compounds, maceration and soxhlet methods are also recommended, respectively. Higher antimicrobial activity achieved in the polar solvents is indicative of the presence of the antimicrobial activity in the polar compounds. On the other side, the resistance to the T. wallichiana extracts in fungi, such as Trichoderma, is indicative of the mutualistic interaction and the possibility of its use as biopesticide.

\section{CONFLICT OF INTEREST STATEMENT}

We declare that we have no conflict of interest.

\section{ACKNOWLEDGEMENTS}

Authors are grateful to Director GBPNIHESD for extending the facilities and National Mission on Himalayan Studies (Ministry of Environment, Forest \& Climate Change, Govt. of India, New Delhi) for financial support.

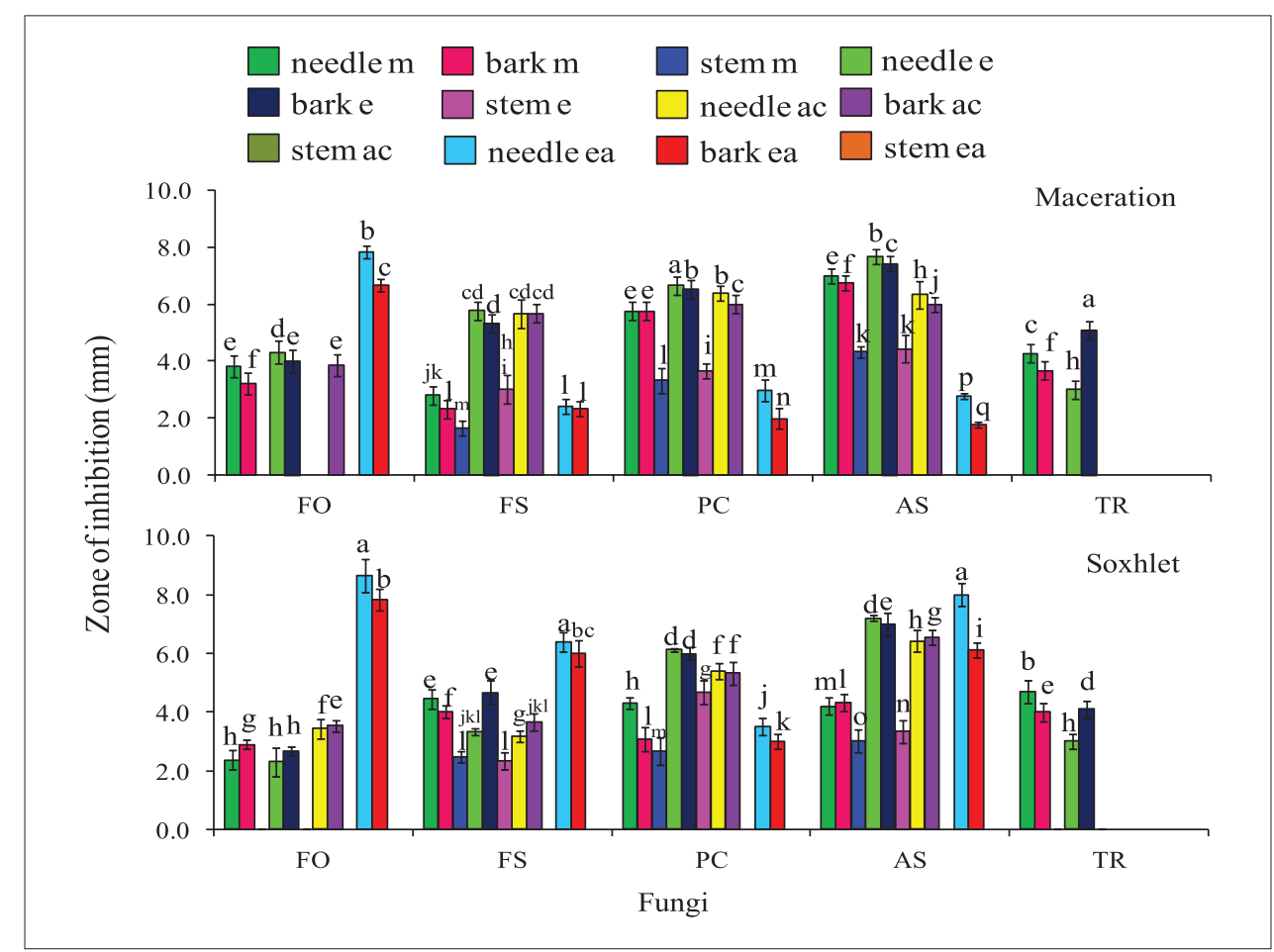

Figure 5: Antifungal activity of needle, stem and bark of $T$. wallichiana. Methanol= $\mathrm{m}$, ethanol= e, acetone $=$ ac, ethyl acetate $=$ ea, $F$. oxysporum= FO, F. saloni= FS, $P$. variotil= PC, A. niger $=$ AS, T. hirsuta $=$ TR. Homogenize grouping done with respect to antifungal activity by Duncan test is denoted by the alphabets a-q 


\section{REFERENCES}

1. Jeelani SM, Rather GA, Sharma A, Lattoo SK. In perspective: Potential medicinal plant resources of Kashmir Himalayas, their domestication and cultivation for commercial exploitation. Journal of Applied Research on Medicinal and Aromatic Plants. 2018; 8:10-25.

2. Sharma N, Kala CP. Harvesting and management of medicinal and aromatic plants in the Himalaya. Journal of Applied Research on Medicinal and Aromatic Plants. 2018; 8:1-9.

3. Pandey A, Agnihotri V. Antimicrobials from medicinal plants: Research initiatives, challenges, and the future prospects. In: Gupta VK, Tuohy MG, O'Donovan A, Lohani L (Eds.), Biotechnology of Bioactive Compounds: Sources and Applications in Food and Pharmaceuticals, John Wiley \& Sons, Ltd. 2015; pp. 123-150.

4. Adhikari P, Pandey A. Taxus wallichiana zucc. (Himalayan Yew) in Antimicrobial Perspective. Advances in Biotechnology and Microbiology. 2017; 4(5): 555-650.

5. Nadeem M, Rikhari HC, Kumar A, Palni LMS, Nandi SK. Taxol content in the bark of Himalayan yew in relation to tree age and sex. Phytochemistry. 2002; 60: 627-631.

6. Uniyal SK. Bark removal and population structure of Taxus wallichiana Zucc. in a temperate mixed conifer forest of western Himalaya. Environmental Monitoring and Assessment. 2013; 185(4): 2921-2928.

7. Sharma H, Garg M. A review of traditional use, phytoconstituents and biological activities of Himalayan yew, Taxus wallichiana. Journal of Integrative Medicine. 2015; 13(2): 80-90.

8. Juyal D, Thawani V, Thaledi S, Joshi M. Ethnomedical properties of Taxus wallichiana Zucc. (Himalayan Yew). Journal of Traditional and Complementary Medicine. 2014; 4(3): 159-161.

9. Fabricant DS, Farnsworth NR. The value of plants used in traditional medicine for drug discovery. Environmental Health Perspectives. 2001; 109: 69-75

10. Tatiya UA, Tapadiya GG, Kotecha S, Surana JS. Effects of solvents on total phenolics, antioxidants and antimicrobial properties of Bridelia retusa Spreng. Stem bark. Indian Journal of Natural Products Research. 2011; 442-447.

11. Sati P, Pandey A, Palni LMS. Antimicrobial potential of leaf extract of Ginkgo biloba L., growing in Uttarakhand India. National Academy Science letters. 2012; 35(3): 201-106.

12. Sarvin B, Stekolshchikova E, Rodin I, Stavrianidi A, Shpigun O. Optimization and comparison of different techniques for complete extraction of saponins from T. terrestris. Journal of Applied Research on Medicinal and Aromatic Plants. 2018; 8: 75-82.

13. Clinical and Laboratory Standard Institute (CLSI). Reference method for broth dilution antifungal susceptibility testing of yeast, $3^{\text {rd }}$ edition. Approved standard M27-A3. CLSI, Wayne; 2008

14. Kazmi N, Hassan W, Hussain S, Khan K, Amir S, Rehman UR, Riaz A Estimation of phytochemicals, inorganic profile and antimicrobial activity of Taxus baccata shoots. Journal of Pure and Applied Microbiology. 2015; 375-382.

15. Felhi S, Daoud A, Hajlaoui H, Mnafgui K, Gharsallah N, Kadri A. Solvent extraction effects on phytochemical constituents profiles, antioxidant and antimicrobial activities and functional group analysis of Ecballium elaterium seeds and peels fruits. Food Science and Technology. 2017; 37(3): 483-492

16. Patel KP, Patel AM, Chaute SB. Antimicrobial activity of various extract from the leaves of Taxus baccata Linn (Taxaceae) Pharmacologyonline; 2009: 217-224.

17. Nisar M, Khan I, Ahmad B, Ali I, Ahmad W, Choudhary IM. Antifungal and antibacterial activities of Taxus wallichiana zucc. Journal of Enzyme Inhibition and Medicinal Chemistry. 2008; 23(2): 256-260.

18. Madhumitha G, Saral AM. Preliminary phytochemical analysis, antibacterial, antifungal and anticandidal activities of successive extracts of Crossandra infundibuliformis. Asian Pacific Journal of Tropical Biomedicine. 2011; 192-195.

19. Rahman TU, Khattak KF, Liaqat W, Choudhary MI. Antibacterial, antifungal, insecticidal, cytotoxic and phytotoxic activities of the crude extracts of Taxus wallichiana Zucc twigs. Journal of Chemical and Pharmaceutical Research. 2016; 8(1): 398-402.

20. Felhi S, Baccouch N, Ben SH, Smaoui S, Allouche N, Gharsallah N, Kadri A. Nutritional constituents, phytochemical profiles, in vitro antioxidant and antimicrobial properties, and gas chromatographymass spectrometry analysis of various solvent extracts from grape seeds, Food Science and Biotechnology. 2016; 25(6): 1537-1544.

21. Biswas NN, Saha S, Ali MK. Antioxidant, antimicrobial, cytotoxic and analgesic activities of ethanolic extract of Mentha arvensis L. Asian Pacific Journal of Tropical Biomedicine. 2014; 4(10): 792-797.

22. Sati P, Dhyani P, Bhatt ID, Pandey A. Ginkgo biloba flavonoids glycoside in antimicrobial perspective with reference to extraction method. Journal of Traditional and Complementary Medicine. 2017; https:// doi.org/10.1016/j.jtcme.2017.10.003.

23. Erdemoglu N, Sener B, Palittapongarnpim P. Antimycobacterial activity of heartwood of Taxus baccata. Pharmaceutical Biology. 2003; 41(8): 614-615.

24. Moustafa AA, Al-Askar AA, Almaary SK, Dawoud MT, Sholkamy NE, Bakri MM. Antimicrobial activity of some plant extracts against bacterial strains causing food poisoning diseases. Saudi Journal Biological Sciences. 2017; 25(2): 361-366. 